\title{
Farelo de gérmen de milho desengordurado na dieta de poedeiras comerciais de 28 a 44 semanas de idade
}

\author{
Sandra Regina Brunelli ${ }^{1}$, João Waine Pinheiro ${ }^{2}$, Nilva Aparecida Nicolao Fonseca ${ }^{2}$, \\ Alexandre $\mathrm{Oba}^{2}$, Caio Abércio da Silva ${ }^{2}$ \\ ${ }^{1}$ Pós-graduação em Zootecnia - Universidade Estadual de Londrina. \\ 2 Departamento de Zootecnia - Universidade Estadual de Londrina.
}

RESUMO - Um experimento foi conduzido para avaliar os efeitos da inclusão de farelo de gérmen de milho desengordurado na dieta de galinhas de 28 a 44 semanas de idade. Foram utilizadas 240 poedeiras Hy-Line W36 distribuídas em delineamento inteiramente casualizado, com seis níveis de farelo de germen de milho desengordurado $(0,6,12,18,24$ e $30 \%$ ), cada um com cinco repetições de oito aves. No período experimental, que durou quatro ciclos de 28 dias, foram avaliados os parâmetros de desempenho das aves (consumo de ração, produção de ovos, peso médio do ovo, massa de ovo e conversão alimentar) e de qualidade dos ovos (gravidade específica, índice de pigmentação da gema, porcentagem de gema e albúmen, porcentagem e espessura da casca e unidade haugh). Os níveis de farelo de gérmen de milho desengordurado tiveram efeito linear negativo sobre o consumo de ração e o índice de pigmentação da gema e efeito quadrático sobre a conversão alimentar. A inclusão de farelo de gérmen de milho desengordurado na dieta não influenciou as outras variáveis estudadas. O farelo de gérmen de milho desengordurado pode ser incluído em níveis de até $21,2 \%$ em rações para galinhas poedeiras.

Palavras-chave: alimento alternativo, desempenho, nutrição, produção de ovos, qualidade dos ovos

\section{Defatted corn germ meal in diets for laying hens from 28 to 44 weeks of age}

\begin{abstract}
This experiment was conducted to evaluate the effect of including defatted corn germ meal in diets for laying hens. It was assigned two hundred and forty laying hens to a randomized design, with six diets and five replicates of eight hens per diet. Experimental diets were formulated by inclusion of defatted corn germ meal at 0, 6, 12, 18, 24 and 30\% level. The period experiment was carried out for four 28-day cycles and performance (feed intake, egg production, egg weight, egg mass and feed conversion) and the egg quality (egg specific gravity, yolk color, yolk and albumen percentages, shell percentages, shell thickness and Haugh unity) were the evaluated parameters. Negative linear effect was observed for feed intake and yolk pigmentation by increasingly including defatted corn germ meal in diets for laying hens. Quadratic effect of defatted corn germ meal for feed conversion was also observed. No statistical differences were observed for any other parameters. Defatted corn germ meal can be included at $21.2 \%$ in laying hens diets.
\end{abstract}

Key Words: alternative feed, egg production, egg quality, nutrition, performance

\section{Introdução}

Vários subprodutos da indústria de processamento de grãos têm potencial para uso na alimentação de aves, mas, para que sejam usados corretamente, necessitam de constante avaliação quanto à sua qualidade nutricional e ao nível de inclusão.

O farelo de gérmen de milho desengordurado é um subproduto da indústria de óleo de milho e tema características nutricionais para uso na alimentação de galinhas poedeiras. O processo de obtenção do gérmen envolve moagem úmida do grão de milho, seguida da secagem, prensagem (Dermachi, 1998) e perfusão por solvente.

O farelo de gérmen de milho desengordurado apresenta valor médio de $2.413 \mathrm{kcal} \mathrm{EM} / \mathrm{kg}, 9,81 \%$ de proteína bruta, $5,29 \%$ de fibra bruta, $0,60 \%$ de extrato etéreo, $6,44 \%$ de matéria mineral e pode ser utilizado em níveis até $20 \%$ em rações para frangos sem comprometer o desempenho nem as características de carcaça (Brunelli et al., 2006).

A concentração de fibra do farelo de gérmen de milho desengordurado pode ser fator limitante ao seu uso em quantidades elevadas na alimentação de poedeiras e frangos de corte. O elevado conteúdo de fibra na ração reduz a 
energia, aumenta a velocidade do trânsito da digesta (Van Soest, 1985) e diminui a digestibilidade dos nutrientes. O farelo de gérmen de milho integral possui em média $6,77 \%$ de fibra em detergente ácido (FDA) e 2,78\% de fibra em detergente neutro (FDN) (Rodrigues et al., 2001).

Outro fator que deve ser considerado na utilização de fonte alternativa ao milho é sua capacidade de conferir pigmentação à gema, que é influenciada pela quantidade de xantofila do alimento (Acker \& Cunningham, 1991). Geralmente o consumidor prefere ovos com gemas mais alaranjadas porque associa esta cor à qualidade do ovo. $\mathrm{O}$ valor médio de xantofila no grão de milho é de $20,09 \mu \mathrm{g} / \mathrm{g}$, portanto superior ao do gérmen de milho $(1,8 \mu \mathrm{g} / \mathrm{g})$ (Moros et al., 2002).

O farelo de gérmen de milho desengordurado apresenta alta concentração de fósforo na forma de fitato (Graf \& Eaton, 1984), o que pode interferir no valor nutricional, diminuindo a biodisponibilidade de outros minerais, de elementos-traços (zinco, ferro, cobre), de proteínas e enzimas digestivas da ração, (Kornegay, 1996), podendo afetar a produção e a qualidade dos ovos (Ravindran et al., 1999).

Diante da escassez de informações sobre esse ingrediente, realizou-se este trabalho com o objetivo de avaliar os efeitos da inclusão de farelo de gérmen de milho desengordurado $(0,6,12,18,24$ e $30 \%)$ na dieta sobre o desempenho e a qualidade dos ovos de galinhas poedeiras de 28 a 44 semanas de idade.

\section{Material e Métodos}

O experimento foi conduzido no setor de avicultura da fazenda-escola da Universidade Estadual de Londrina. Foram utilizadas 240 poedeiras Hy-Line W36, com 28 semanas de idade durante 112 dias, divididos em quatro ciclos de 28 dias.

As poedeiras foram alojadas em 30 gaiolas instaladas em um galpão convencional para postura, com $24 \mathrm{~m}$ de comprimento, 5,50 $\mathrm{m}$ de largura e 2,80 $\mathrm{m}$ de pé-direito, com cobertura de telhas de fibrocimento. Cada gaiola de arame galvanizado média $100 \mathrm{~cm}$ de comprimento (divididas em dois compartimentos de $50 \mathrm{~cm}$ ) $\times 45 \mathrm{~cm}$ profundidade $\times 40 \mathrm{~cm}$ de altura e alojava oito poedeiras, constituindo a unidade experimental. Os bebedouros eram do tipo copo e dispostos lateralmente entre as divisórias das gaiolas, atendendo quatro aves cada um. Os comedouros do tipo calha, eram de madeira e instalados à frente das gaiolas. As aves receberam água e alimento à vontade durante todo o período experimental, num programa com 17 horas de luz por dia.

O delineamento experimental foi inteiramente casualizado, com seis rações, cada uma com um nível de inclusão de farelo de gérmen de milho desengordurado $(0,6,12,18,24$ e $30 \%)$, avaliadas em cinco repetições de oito aves. As rações (Tabela 1) foram formuladas utilizando-se os valores nutricionais dos alimentos e as exigências

Tabela 1 - Composição das rações experimentais

\begin{tabular}{|c|c|c|c|c|c|c|}
\hline \multirow[t]{2}{*}{ Ingrediente $(\%)$} & \multicolumn{6}{|c|}{ Farelo de gérmen de milho desengordurado (\%) } \\
\hline & 0 & 6 & 12 & 18 & 24 & 30 \\
\hline Milho & 63,79 & 57,39 & 51,00 & 44,60 & 38,22 & 31,83 \\
\hline Farelo soja & 22,93 & 22,37 & 21,78 & 21,17 & 20,57 & 19,97 \\
\hline Farelo de gérmen de milho desengordurado & 0,00 & 6,00 & 12,00 & 18,00 & 24,00 & 30,00 \\
\hline Óleo vegetal & 1,48 & 2,44 & 3,39 & 4,36 & 5,32 & 6,28 \\
\hline Fosfato bicálcico & 1,52 & 1,47 & 1,42 & 1,38 & 1,33 & 1,28 \\
\hline Calcário & 9,25 & 9,25 & 9,25 & 9,26 & 9,26 & 9,26 \\
\hline Sal & 0,48 & 0,48 & 0,48 & 0,49 & 0,49 & 0,50 \\
\hline DL-metionina $(99 \%)$ & 0,15 & 0,18 & 0,22 & 0,25 & 0,28 & 0,31 \\
\hline L-lisina $\mathrm{HCl}(79 \%)$ & 0,00 & 0,02 & 0,06 & 0,09 & 0,13 & 0,17 \\
\hline Suplemento vitamínico+mineral ${ }^{1}$ & 0,40 & 0,40 & 0,40 & 0,40 & 0,40 & 0,40 \\
\hline \multicolumn{7}{|l|}{ Valores calculados } \\
\hline Energia metabolizável (kcal/kg) & 2.800 & 2.800 & 2.800 & 2.800 & 2.800 & 2.800 \\
\hline Proteína bruta $(\%)$ & 16,00 & 16,00 & 16,00 & 16,00 & 16,00 & 16,00 \\
\hline Cálcio (\%) & 4,02 & 4,020 & 4,02 & 4,02 & 4,02 & 4,02 \\
\hline Sódio $(\%)$ & 0,22 & 0,22 & 0,22 & 0,22 & 0,22 & 0,22 \\
\hline Fósforo disponível (\%) & 0,37 & 0,37 & 0,37 & 0,37 & 0,37 & 0,37 \\
\hline Lisina total $(\%)$ & 0,76 & 0,80 & 0,82 & 0,84 & 0,86 & 0,88 \\
\hline Metionina total (\%) & 0,41 & 0,44 & 0,46 & 0,49 & 0,52 & 0,55 \\
\hline Metionina + cistina total $(\%)$ & 0,68 & 0,68 & 0,68 & 0,68 & 0,68 & 0,68 \\
\hline Fibra bruta $(\%)$ & 2,60 & 2,78 & 2,96 & 3,13 & 3,31 & 3,47 \\
\hline Extrato etéreo $(\%)$ & 4,15 & 4,90 & 5,67 & 6,41 & 7,16 & 8,25 \\
\hline
\end{tabular}

${ }^{1}$ Suplemento vitamínico mineral aminoacídico por kg de produto: vit. A - 2.500 .000 UI; vit. B1 - 350 mg; vit. B12 - 2.750 mcg; vit. B2 - $1.250 \mathrm{mg}$, vit. B6 - 500 mg; vit. D3 - $625.000 \mathrm{UI}$; vit. E - $1.500 \mathrm{mg}$; vit. K $400 \mathrm{mg}$; ácido fólico - $100 \mathrm{mg}$; ácido pantotênico - $2.500 \mathrm{mg}$; cobre - $2.000 \mathrm{mg}$; ferro - $12.500 \mathrm{mg}$; zinco - 12.500 ; iodo $187,5 \mathrm{mg}$; mangânes - $18.750 \mathrm{mg}$; metionina - $172,5 \mathrm{~g}$; niacina - $6.250 \mathrm{mg}$; selênio - $75 \mathrm{mg}$; antioxidante - 2,5 g; veículo Q.S.P. - 1.000 g. 
nutricionais preconizados por Rostagno et al. (2000), à exceção do farelo de gérmen de milho desengordurado, cujos valores nutricionais considerados foram aqueles indicados por Brunelli et al. (2006).

Ao final de cada ciclo de 28 dias, foram avaliadas as características de desempenho (consumo de ração; produção de ovos, peso médio dos ovos, massa de ovos, e conversão alimentar), as características de qualidade dos ovos determinadas pela gravidade específica, o índice de pigmentação da gema, as porcentagens de gema, de albúmen e casca, a espessura de casca e a unidade haugh.

O consumo de ração de cada parcela foi calculado pela diferença entre o fornecido no início e as sobra ao final de cada ciclo. O consumo de ração de cada ave foi calculado dividindo-se o consumo na parcela pelo número de aves, e, nas parcelas que ocorreram mortes, dividiu-se o consumo pela média ponderada de aves no período. A produção de ovos de cada parcela foi registrada diariamente, sendo calculada em porcentagem, dividindo-se a quantidade de ovos produzidos pelo número de aves de cada parcela. $\mathrm{O}$ peso médio dos ovos foi estimado pelo peso dos ovos produzidos nos últimos três dias de cada ciclo. A massa de ovos correspondeu ao produto da produção de ovos pelo peso médio dos ovos da parcela. A conversão alimentar por massa de ovo foi calculada por meio da relação entre o consumo de ração e a massa de ovo produzida.

Todos os ovos dos últimos dois dias de cada ciclo de 28 dias foram coletados, identificados e transportados para uma sala de ovos, onde foram armazenados em temperatura ambiente por 24 horas. Os ovos íntegros de cada unidade experimental foram mergulhados em sete soluções salinas com densidade de 1,080 a $1,098 \mathrm{~g} / \mathrm{cm}^{3}$, com gradiente de 0,003 entre elas, para estimar a gravidade específica de acordo com a técnica de flutuação salina proposta por Hamilton (1982).

Posteriormente, dois ovos de cada unidade experimental foram identificados, pesados e quebrados a fim de se obter o índice de pigmentação da gema com auxílio de um leque calorimétrico Roche. Também foram obtidos os pesos de gema, albúmen e casca, correlacionando-os com o peso do ovo, com valores expressos percentualmente. Após separação e lavagem, as cascas ficaram expostas por 72 horas à temperatura ambiente e em seguida foram pesadas. Os percentuais foram obtidos dividindo-se o peso de cada uma dessas variáveis pelo peso do ovo e, em seguida, multiplicando-se o resultado por 100 . Também foi obtida a altura do albúmen, utilizando-se micrometro, para o cálculo da unidade haugh.
As espessuras das cascas foram determinadas por meio de um paquímetro digital, em quatro pedaços de 3 a $5 \mathrm{~mm}^{2}$, retirados de quatro regiões diferentes de cada casca de ovo. Os valores de cada ovo foram transformados no valor médio de cada unidade experimental.

Para identificação da unidade haugh, utilizaram-se os valores dos pesos dos ovos e da altura do albúmen. Os resultados foram obtidos pela fórmula sugerida por Stadelman \& Cotteril(1986), $\mathrm{UH}=100 \times \log \left(\mathrm{H}+7,57-1,7 \mathrm{~W}^{0,37}\right)$, em que: $\mathrm{H}=$ altura do albúmen $(\mathrm{mm}) ; 7,57$ = fator de correção para altura do albúmen; 1,7 = fator de correção para peso do ovo e $\mathrm{W}=$ peso do ovo $(\mathrm{g})$.

Os valores médios dos parâmetros analisados foram submetidos à análise de variância pelo programa SAEG (UFV, 2000). Foram realizadas análises de regressão para os efeitos significativos dos níveis de farelo de gérmen de milho desengordurado, considerando-se até o efeito quadrático.

\section{Resultados e Discussão}

As rações foram formuladas para conter os mesmos níveis nutricionais, porém as quantidades de fibra bruta $\mathrm{e}$ de gordura variaram com a inclusão do farelo de gremen de milho desengordurado e de óleo de soja. O valor energético do farelo de gérmen de milho desengordurado é inferior ao milho, por este motivo, foi necessário fazer a correção energética das rações com adição de óleo de soja, o que causou variações no seu teor de gordura.

Os níveis de inclusão de farelo de gérmen de milho desengordurado tiveram efeito linear decrescente $(\mathrm{P}<0,05)$ (Tabela 2) no consumo de ração, $\hat{Y}=102,946-0,158102 X$ $\left(\mathrm{R}^{2}=0,59\right)$. Esse resultado difere do obtido por Brito et al. (2005) que constataram aumento no consumo quando substituíram $100 \%$ do milho em por farelo de gérmen de milho integral em rações para poedeiras. Os autores atribuíram o resultado à menor densidade da ração contendo alta quantidade de fibra e de gordura nas rações.

A inclusão de $30 \%$ de farelo de gérmen de milho desengordurado aumentou em $34 \%$ a concentração de fibra dietética em relação à ração isenta do produto e demandou maior quantidade de óleo de soja para correção de seu nível energético. Lima et al. (2007) avaliaram o desempenho de poedeiras alimentadas com rações contendo farelo de coco $(0,5,10,15$ e $20 \%)$, assim como Samli et al. (2006), com farelo de arroz $(0,5,10,15$ e 20\%), observaram também menores consumos para as rações com maiores concentrações de fibra, fato que associaram à correção da energia com a adição de óleo vegetal. 
Tabela 2 - Desempenho de poedeiras de 28 a 44 semanas de idade alimentadas com rações com diferentes níveis de farelo de gérmen de milho desengordurado

\begin{tabular}{|c|c|c|c|c|c|c|c|c|c|}
\hline & \multicolumn{6}{|c|}{ Farelo de gérmen de milho desengordurado $(\%)$} & \multirow[t]{2}{*}{ Média } & & \multirow{2}{*}{$\begin{array}{l}\text { CV } \\
(\%)\end{array}$} \\
\hline & 0 & 6 & 12 & 18 & 24 & 30 & & & \\
\hline Consumo de ração (g/ave/dia) & 105,13 & 100,82 & 99,56 & 99,26 & 99,07 & 99,60 & 100,57 & $\mathrm{~L}^{*}$ & 4,04 \\
\hline Peso médio dos ovos $(\mathrm{g})$ & 59,84 & 59,83 & 60,15 & 59,87 & 59,51 & 59,31 & 59,75 & NS & 2,96 \\
\hline Massa de ovos (g/ave/dia) & 56,22 & 54,39 & 55,88 & 56,49 & 56,29 & 56,66 & 55,99 & NS & 4,47 \\
\hline Conversão alimentar $(\mathrm{g} / \mathrm{g})$ & 1,87 & 1,82 & 1,76 & 1,72 & 1,74 & 1,76 & 1,78 & $\mathrm{Q}^{*}$ & 3,69 \\
\hline
\end{tabular}

$\mathrm{CV}=$ Coeficiente de variação; NS = Não-significativo; $\mathrm{L}^{*}$ - Efeito linear $(\mathrm{P}<0,05) ; \mathrm{Q}^{*}$ - Efeito quadrático $(\mathrm{P}<0,05)$.

O aumento no teor de gordura das dietas com a adição de óleo de soja pode ter sido determinante da diminuição do consumo de ração. Bohnsack et al. (2002) e Antar et al. (2004) também observaram redução no consumo de ração quando adicionaram gordura às dietas de poedeiras comerciais. Segundo Mateos \& Sell (1981) e Mateos et al. (1982), o consumo diminui em dietas acrescidas de gordura, uma vez que a dieta provoca redução na taxa de passagem do alimento pelo trato gastrintestinal. A presença de soluções lipídicas no duodeno estimula a liberação do hormônio colecistoquinina (CCK), que atua no reflexo enterogástrico diminuindo a velocidade de esvaziamento do sistema digestório (Swenson \& Reece, 1966).

Os níveis de farelo de gérmen de milho desengordurado nas rações não afetaram $(\mathrm{P}>0,05)$ a produção, o peso médio e a massa dos ovos (Tabela 2). Araújo et al. (2008) e Samli et al. (2006) observaram que poedeiras alimentadas com dietas com níveis elevados de farelo de trigo (30\%) e de farelo de arroz (15\%), ou seja com alta concentração de fibra, tiveram menores taxas de postura. Rodrigues et al. (2005) observaram efeito benéfico da adição do óleo de soja $(2,4,6$ e $8 \%)$ nas dietas das aves e notaram melhores resultados ( $83,8 \%$ de postura) no nível máximo de inclusão de óleo $(8 \%)$. Como não foram observados efeitos dos níveis de farelo de gérmen de milho desengordurado nas rações sobre a produção de ovos, supõe-se que os nutrientes contidos nas dietas não interferiram nestas características.

O peso do ovo é influenciado principalmente pela quantidade de aminoácidos sulfurados totais da dieta (Sohail et al., 2002). De acordo com Leeson \& Summer (2001), a metionina é o aminoácido com maior efeito no peso do ovo. Rodrigues et al. (2001) determinaram menor coeficiente de digestibilidade da metionina no farelo de gérmen de milho integral em relação ao milho e demonstraram necessidade de sua suplementação, na forma sintética, quando adicionaram o farelo na raçãodas poedeiras.

A massa de ovo não foi afetada pelos níveis de farelo de gérmen de milho desengordurado às rações, o que se explica pelo fato de que as variáveis envolvidas no cálculo nãoforam afetadas pela inclusão do produto.

A conversão alimentar, expressa pela relação entre consumo de ração e a massa de ovos, aumentou de forma quadrática $(\mathrm{P}<0,05)$ de acordo com os níveis de farelo de gérmen de milho desengordurado nas rações ( $\hat{Y}=1,87597$ $\left.0,0135647 \mathrm{X}+0,000320387 \mathrm{X}^{2}, \mathrm{R}^{2}=0,94\right)($ Tabela 2$)$. A derivação da equação comprovou que o melhor índice de conversão alimentar foi obtido com $21,2 \%$ de farelo de gérmen de milho desengordurado (Figura 1). Com frangos de corte, Brunelli et al. (2006) determinaram melhor conversão alimentar com a inclusão de $20 \%$ de farelo de gérmen de milho desengordurado às rações. $\mathrm{O}$ comportamento quadrático registrado para esta característica deve-se à redução do consumo de ração sem alteração expressiva na massa de ovos. Esse efeito positivo na conversão alimentar pode estar relacionado à adição de óleo nas rações que, ao elevar o tempo de passagem do alimento pelo trato gastrintestinal, melhorou na digestibilidade e a absorção dos nutrientes da dieta (Mateos \& Sell, 1981; Ghazalah et al., 2008).

A gravidade específica dos ovos não foi afetada $(\mathrm{P}>0,05)$ pelos níveis de farelo de gérmen de milho desengordurado (Tabela 3). A gravidade específica é uma

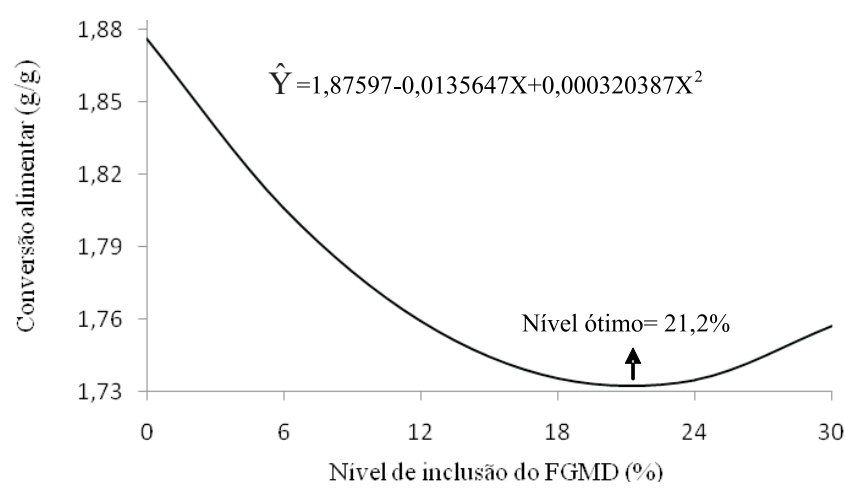

Figura 1 - Conversão alimentar de poedeiras comerciais alimentadas com rações contendo diferentes níveis de farelo de gérmen de milho desengordurado. 
Tabela 3 - Qualidade do ovo de poedeiras de 28 a 44 semanas de idade alimentadas com rações com diferentes níveis de farelo de gérmen de milho desengordurado

\begin{tabular}{|c|c|c|c|c|c|c|c|c|c|}
\hline & \multicolumn{6}{|c|}{ Farelo de gérmen de milho desengordurado (\%) } & \multirow[t]{2}{*}{ Média } & & \multirow{2}{*}{$\begin{array}{l}\mathrm{CV} \\
(\%)\end{array}$} \\
\hline & 0 & 6 & 12 & 18 & 24 & 30 & & & \\
\hline Gravidade específica $\left(\mathrm{g} / \mathrm{cm}^{3}\right)$ & 1,088 & 1,089 & 1,089 & 1,088 & 1,088 & 1,088 & 1,088 & NS & 0,11 \\
\hline Porcentagem de gema $(\%)$ & 26,19 & 26,19 & 25,81 & 26,03 & 26,11 & 26,03 & 26,06 & NS & 2,01 \\
\hline Porcentagem de albúmen (\%) & 64,99 & 64,88 & 65,23 & 64,72 & 64,83 & 65,03 & 64,95 & NS & 0,99 \\
\hline Porcentagem de casca $(\%)$ & 9,74 & 9,80 & 9,86 & 9,81 & 9,84 & 9,73 & 9,80 & NS & 1,79 \\
\hline
\end{tabular}

$\mathrm{L}^{* *}=$ Efeito linear $(\mathrm{P}<0,01) ; \mathrm{NS}=$ Não-significativo; $\mathrm{CV}=$ Coeficiente de variação.

estimativa da quantidade de casca depositada e está relacionada à sua porcentagem. Os valores obtidos para esta característica comprovaram boa qualidade da casca do ovo. Segundo Scott (1995), o valor de 1,08 constitui um ponto de referência para boa qualidade da casca do ovo. De acordo com Hamilton (1982), a gravidade específica do ovo reduz à medida que a espessura da casca diminui, o que leva à redução de sua resistência à quebra. A espessura da casca não foi influenciada $(\mathrm{P}>0,05)$ pelos níveis de farelo de gérmen de milho desengordurado.

O índice de pigmentação da gema reduziu de forma linear, conforme aumentaram os níveis de farelo de gérmen de milho desengordurado ( $\hat{Y}=6,28488-0,0523810 \mathrm{X}$, $\mathrm{R}^{2}=0,89$ ) (Tabela 3). Brito et al. (2005) também observaram diminuição da pigmentação da gema de ovos de poedeiras alimentadas com farelo de gérmen de milho integral. Como o grão de milho possui maior concentração de xantofila $(20,09 \mu \mathrm{g} / \mathrm{g})$ em relação ao gérmen de milho $(1,88 \mu \mathrm{g} / \mathrm{g})$ (Moros et al., 2002), a redução na pigmentação da gema pode ter ocorrido pela menor quantidade do pigmentante.

A porcentagem de gema e de albúmen é calculada em relação ao peso do ovo e não foi influenciada $(\mathrm{P}>0,05)$ pelos níveis de farelo de gérmen de milho desengordurado na dieta (Tabela 3). Yannakopoulos \& Tserveni-gousi (1996) comentaram que o peso do ovo e a proporção de seus componentes aumentam conforme a idade da poedeira. Segundo Peebles et al. (2000), as características dos ovos não são influenciadas apenas pela idade das aves, mas também pela sua dieta. Assim, quando a dieta apresenta maior teor de gordura, o peso das gemas aumenta, o que não foi observado neste experimento. Os percentuais médios de gema $(26,06 \%)$ e de albúmen (64,95\%) foram semelhantes aos citados por Madrid (1981).

A casca deve resistir à ovopostura, à colheita, à classificação e ao transporte do ovo (Kussakawa et al., 1998). A inclusão de farelo de gérmen de milho desengordurado às rações não influenciou $(\mathrm{P}>0,05)$ a qualidade da casca, a porcentagem e espessura de casca e a gravidade específica do ovo.

A porcentagem de casca corresponde ao seu peso em relação ao peso do ovo. Ovos maiores e mais pesados possuem cascas mais finas e em menores proporções em relação ao peso do ovo. Como não houve efeito dos níveis de farelo de gérmen de milho desengordurado no peso dos ovos, também não foram observados efeitos na espessura das cascas. Araújo et al. (2008), trabalhando com farelo de trigo, alimento rico em ácido fítico, não observaram efeitos de sua inclusão na ração sobre a porcentagem da casca dos ovos. Este fato indica que o ácido fítico do farelo de gérmen de milho desengordurado não foi capaz de influenciar a qualidade das cascas.

As médias das unidades haugh demonstraram que a inclusão do farelo de gérmen de milho desengordurado nas rações não afetou esta variável (Tabela 3). A unidade haugh é uma medida da avaliação da qualidade interna do ovo que relaciona a altura do albúmen do peso do ovo. Ewing (1963) relatou que a altura do albúmen não é influenciada pela dieta. Brito etal.(2005) também não evidenciaram alteração na unidade haugh dos ovos relacionada às concentrações de farelo de gérmen de milho integral nas rações. Samli et al. (2006) observaram diferenças na unidade Haugh dos ovos de poedeiras alimentadas com $15 \%$ de farelo de $\operatorname{arroz}(102,2 \mathrm{UH})$ em relação a um grupo de poedeiras alimentadas com dieta controle $(96,0 \mathrm{UH})$ e relacionaram este resultado à qualidade da proteína e à concentração de gordura no farelo de arroz.

\section{Conclusões}

Considerando a conversão alimentar e o índice de pigmentação da gema, o farelo de gérmen de milho desengordurado pode ser incluído em quantidades equivalentes a até $21,2 \%$ em dietas para galinhas poedeiras de 28 a 44 semanas de idade. 


\section{Referências}

ACKER, D.; CUnNIngham, M. Animal science and industry. 4.ed. Engwood Cliffs: Prentice-Hall, 1991. 709p.

ANTAR, R.S.; HARMS, R.H.; SHIVAZAD M. et al. Performance of commercial laying hens when six percent corn oil is added to the diet at various ages and with different levels of tryptophan and protein. Poultry Science, v.83, n.3, p.447-455, 2004.

ARAUJO, D.M.; SILVA, J.H.V.; ARAUJO, J.A. et al. Farelo de trigo na alimentação de poedeiras semipesadas na fase de recria. Revista Brasileira de Zootecnia, v.37, n.1, p.67-72, 2008.

BRITO, A.B.; STRINGHINI, J.H.; BELEM, L.M. et al. Desempenho e qualidade dos ovos de poedeiras comerciais de 30 a 64 semanas de idade consumindo gérmen integral de milho. Acta Scientiarum Animal Sciences, v.27, n.1, p.29-34, 2005.

BOHNSACK, C.R.; HARMS, R.H.; MERKEL, W.D. et al. Performance of commercial layers when fed diets with four levels of corn oil or poultry fat. Journal Applied Poultry Research, v.11, n.1, p.68-76, 2002.

BRUNELLI, S.R.; PINHEIRO, J.W.; SILVA, C.A. et al. Inclusão de farelo de gérmen de milho desengordurado na alimentação de frangos de corte. Revista Brasileira de Zootecnia, v.35, n.4, p.1349-1358, 2006.

DERMACHI, J.J.A.A. Bovinos leiteiros. In: SIMPÓSIO DE NUTRIÇÃO ANIMAL, 1., 1998, Espirito Santo do Pinhal. Anais... Espírito Santo do Pinhal: Fundação Pinhalense de Ensino, 1998. p.117-130.

EWING, W.R. Poultry nutrition. 5.ed. Pasadena: Ray Ewing Co., 1963. 1475 p.

GRAF, E.; EATON, J.W. Effects of phytate on mineral bioavailability in mice. The Journal of Nutrition, v.114, n.7, p.1192-1198, 1984 .

GHAZALAH, A.A.; ABD, M.O.; ALI, A.M. et al. Influence of dietary energy and poultry fat on the response of broiler chicks to heat therm. Poultry Science, v.4, n.7, p.355-359, 2008.

HAMILTON, R.M.G. Methods and factors that affect the measurement of egg shell quality. Poultry Science, v.61, n.6, p.2022-2039, 1982 .

KORNEGAY, E.T. Effect of phytase on the bioavailability of phosphorus, calcium, amino acids, and trace minerals in broilers and turkeys. In: BASF TECHNICAL SYMPOSIUM. WORLD CONGRESS CENTER, 1996, Atlanta, Georgia. Proceedings.... Atlanta, 1996. p.39-70.

KUSSAKAWA, K.C.K.; MURAKAMI, A.E.; FURLAN, A.C. Combinações de fontes de cálcio em rações de poedeiras na fase final de produção e após muda forçada. Revista Brasileira de Zootecnia, v.27, n.3, p.572-578, 1998

LEESON, S.; SUMMERS, J.D. Scott's nutrition of the chicken. 4.ed. Ghelph: University Books, 2001. 591p.

LIMA, R.C.; FUENTES, M.F.F.; FREITAS, E.R. et al. Farelo de coco na ração de poedeiras comerciais: digestibilidade dos nutrientes, desempenho e qualidade dos ovos. Revista Brasileira de Zootecnia, v.36, n.5, p.1340-1346, 2007.
MADRID, A. Manual de indústrias alimentaria. Madrid: Mundi-Prensa, 1981. 565p.

MATEOS, G.G.; SELL, J.L. Influence of fat and carbohydrate source on Rate of food passage of semi purified diets for laying hens. Poultry Science, v.60, n.12, p.2114-2119, 1981.

MATEOS, G.G.; SELL, J.L.; EASTWOOD, J.A. Rate of food passage (transit time) as influenced by level of supplemental fat. Poultry Science, v.61, n.1, p.94-100, 1982.

MOROS, E.E.; DARNOKO, D.; CHERYAN, M. et al. Analysis of xanthophylls in corn by HPLC. Journal Agriculture Food Chemistry, v.50, n.21, p.5787-5790, 2002 .

PEEBLES, E.D.; ZUMWALT, C.D.; DOYLE, S.M. et al. Effects of breeder age and dietary fat source and level on broiler hatching egg characteristics. Poultry Science, v.79, n.5, p.698-704, 2000 .

RAVINDRAN, V.; CABAHUG, S.; RAVINDRAN, G. et al. Influence of microbial phytase on apparent ileal amino acid digestibility of feedstuffs for broiler. Poultry Science, v.78, n.5, p.699706, 1999 .

RODRIGUES, P.B.; ROSTAGNO, H.S.; ALBINO, L.F.T. et al Aminoácidos digestíveis verdadeiros do milheto, do milho e subprodutos do milho, determinados com galos adultos cecectomizados. Revista Brasileira de Zootecnia, v.30, n.6, p.2046-2058, 2001.

RODRIGUES, E.A.; CANCHERINI, L.C.; JUNQUEIRA, O.M. et al. Desempenho, qualidade da casca e perfil lipídico de gemas de ovos de poedeiras comerciais alimentadas com níveis crescentes de óleo de soja no segundo ciclo de postura. Acta Scientiarum Animal Sciences, v.27, n.2, p.207-212, 2005.

ROSTAGNO, H.S.; ALBINO, L.F.T.; DONZELE, J.L. et al. Tabelas brasileiras para aves e suínos: composição de alimentos e exigências nutricionais. Viçosa, MG: Universidade Estadual de Viçosa, 2000. 141p

SAMLI, H.E.; SENKOYLU, N.; AKYUREK, H. et al. Using rice bran in laying hen diets. Journal Central European Agriculture, v.7, n.1, p.135-140, 2006.

SCOTT, M.L. Tips to improve egg Shell quality. Feedstuffs, v.67, n.33, p.18, 1995.

SOHAIL, S.S.; BRYANT, M.M.; ROLAND, D.A. Influence of supplemental lysine, isoleucine, threonine, tryptophan and total sulfur amino acids on egg weight of Hy-Line W-36 hens. Poultry Science, v. 81, n.7, p.1038-1044, 2002.

STADELMAN, W.J.; COTTERIL, O.J. Egg science and technology. 3.ed. New York: Food Products Press, 1986. 499p.

SWENSON, M.J.; REECE, W.O. Dukes: Fisiologia dos animais domésticos. Rio de Janeiro: Guanabara, 1966. 856p.

UNIVERSIDADE FEDERAL DE VIÇOSA - UFV. Sistema de análises estatísticas e genéticas - SAEG. Versão 8.0. Viçosa, MG, 2000. 142p.

VAN SOEST, P.J. Definition of fibre in animal feeds. In: HARESIGN, W.; COLE, D.J.A (Eds). Recent advances in animal nutrition. London: Butterworth, 1985. p.55-70.

YANNAKOUPOULOS, A.L.; TSERVENI-GOUSI, A.S. Quality characteristics of quail eggs. British Poultry Science, v.27, n.2, p.171-176, 1986. 